\title{
The Influence of Interaction between Cadmium with $17 \beta$-Estradiol, 2-Methoxyestradiol and $16 \alpha$-Hydroxyestrone on Viability and P-Glycoprotein in Ovarian Cancer Cell Line
}

\author{
Ewa Sawicka ${ }^{1, *}$, Jolanta Saczko ${ }^{2}$, Julita Kulbacka ${ }^{2} \oplus$, Martyna Szydełko ${ }^{3}$, Beata Szymańska ${ }^{1}$ \\ and Agnieszka Piwowar ${ }^{1}$ \\ 1 Department of Toxicology, Faculty of Pharmacy, Wroclaw Medical University, Borowska 211, 50-556 Wroclaw, \\ Poland; beata.szymanska@umw.edu.pl (B.S.); agnieszka.piwowar@umw.edu.pl (A.P.) \\ 2 Department of Molecular and Cellular Biology, Faculty of Pharmacy, Wroclaw Medical University, \\ Borowska 211A, 50-556 Wroclaw, Poland; jolanta.saczko@umw.edu.pl (J.S.); julita.kulbacka@umw.edu.pl (J.K.) \\ 3 Students' Scientific Society, Department of Toxicology, Faculty of Pharmacy, Wroclaw Medical University, \\ Borowska 211, 50-556 Wroclaw, Poland; martyna.szydelko@gmail.com \\ * Correspondence: ewa.sawicka@umed.wroc.pl; Tel.: +48-71-784-04-55-50-556
}

Citation: Sawicka, E.; Saczko, J.; Kulbacka, J.; Szydełko, M.;

Szymańska, B.; Piwowar, A. The Influence of Interaction between Cadmium with $17 \beta$-Estradiol,

2-Methoxyestradiol and

$16 \alpha$-Hydroxyestrone on Viability and P-Glycoprotein in Ovarian Cancer Cell Line. Int. J. Mol. Sci. 2022, 23 , 2628. https://doi.org/10.3390/ ijms 23052628

Academic Editor: Noriyuki Koibuchi

Received: 26 January 2022

Accepted: 24 February 2022

Published: 27 February 2022

Publisher's Note: MDPI stays neutral with regard to jurisdictional claims in published maps and institutional affiliations.

Copyright: (C) 2022 by the authors. Licensee MDPI, Basel, Switzerland. This article is an open access article distributed under the terms and conditions of the Creative Commons Attribution (CC BY) license (https:// creativecommons.org/licenses/by/ $4.0 /)$

\begin{abstract}
Occupational and environmental exposure to xenoestrogens, a subgroup of endocrine disruptors (EDCs), can affect the endocrine system and increase the risk of cancer, primarily the hormone-dependent kind. This type of cancer includes ovarian cancer, which is the leading cause of death from gynecological tumors. The aim of this study was to assess the role of $17 \beta$-estradiol and its metabolites: 2-MeOE2, $16 \alpha-\mathrm{OHE} 1$ in exposure to the metalloestrogen cadmium. The effect of interactions of cadmium with estrogens on the viability of cells in malignant ovarian cancer cells SKOV-3 was investigated, both in simultaneous action and in the pre-incubation model. There are no known interactions between estrogens and cadmium in ovarian cancer cells. Due to the frequent occurrence of multidrug resistance (MDR) in ovarian cancer, the effects of estrogens and cadmium on MDR in SKOV-3, measured as P-glycoprotein (P-gp), were assessed. An interaction study showed that $\mathrm{E} 2$ had an antagonistic effect on cadmium-induced cell damage, while 2-MeOE2 showed less of a protective effect in combination with $\mathrm{CdCl}_{2}$ than E2. There were two types of interaction: toxic synergism and beneficial antagonism. E2 and cadmium increased P-gp expression in SKOV-3 cells, while 2-MeOE2 decreased P-gp expression to a potentially beneficial effect on MDR prevention. The obtained results constitute an interesting starting point for further research in the field of interactions between estrogens and xenoestrogens in ovarian cancer.
\end{abstract}

Keywords: ovarian cancer; cadmium; $17 \beta$-estradiol; 2-methoxyestradiol; $16 \alpha$-hydroxyestrone; Pglycoprotein

\section{Introduction}

Cadmium is a highly toxic non-essential transition metal that constitutes an important potential health risk to the environment [1]. Multiple mechanisms potentially relate cadmium to cancer; these include oxidative stress or inflammation, interference with DNA repair and changes of DNA methylation. More importantly in respect to hormone-related cancers, there is evidence that cadmium may act on estrogenic signaling pathways, resulting, among others, in the proliferation of breast cancer cells in vitro [2,3]. The literature data on the effect of cadmium on breast cancer are numerous, but there is little data on ovarian cancer (OCa). This study analyzes the available data from the Third National Health and Nutrition Examination Survey, which suggests a link between exposure to cadmium and increased mortality from ovarian cancer [4]. Moreover, García-Perez et al. [2015] revealed a statistically significant increase in the incidence of, and mortality from, ovarian cancer in the proximity of cadmium-emitting refineries [5]. 
Ovarian cancer is the leading cause of death from gynecologic malignancies. The highest rates of death (11.4 per 100,000 and 6.0 per 100,000, respectively) are seen in Eastern and Central Europe. Ovarian cancer is the second most common malignancy after breast cancer in women over the age of 40, particularly in developed countries [6,7]. Epidemiological studies have shown the importance of hormonal factors in the pathogenesis of OCa [8]. The relationship between estrogens and ovarian cancer is not so clear, but recent findings from a reanalysis of the epidemiological data suggest an elevated risk of ovarian cancer with estrogen and progesterone therapy or estrogen therapy only. The available data have shown that ovarian cancer cells are associated with a number of estrogen-regulated pathways, similarly to other hormone-dependent cancers [9]. An increase in 17 $\beta$-estradiol (E2) is often observed in ovarian cancer. E2 is known to induce the proliferation of ovarian cancer cells by inhibiting cell-to-cell adhesion, which may cause metastasis $[10,11]$.

The presence of xenoestrogens known as endocrine disrupting compounds (EDC) in occupational and environmental exposure may have an effect on the endocrine system and increase the risk of cancer, mainly hormone-dependent cancer [12]. Some xenobiotics can influence estrogen metabolism by inducing or inhibiting it. Many xenobiotics act as inducers or inhibitors of enzymes, including those involved in the metabolism of estrogens [13]. There are very little data in the literature regarding the influence of EDC on the pathogenesis of ovarian cancer. Park et al. [12] showed that activation of the estrogen response element (ERE) is involved in the proliferation of ovarian cancer cells. It is important to investigate the interactions of estrogens with carcinogens (e.g., cadmium), as estrogen itself is carcinogenic, and synergism with carcinogenic cadmium may potentially be harmful to health. Exposure to metals, including cadmium, is widespread, therefore the explanation of the role of these compounds in the development of hormone-dependent cancers may have important implications for disease prevention.

There has been increased interest in the role of estrogen metabolites in ovarian cancer pathogenesis, as metabolites can often be more toxic than estrogens themselves, e.g., causing DNA damage by creating mutagenic DNA adducts and generating oxygen free radicals. Estrogen metabolism proceeds through the hydroxylation of the A ring, and then 2- or 4-hydroxyl derivatives are formed. Hydroxylation of the D ring (at position 16 $\alpha$ ) may also take place [14]. For example, during estradiol biotransformation, 2-hydroxyestradiol (2OHE2), 2-methoxyestradiol (2-MeOE2), 4-hydroxyestradiol (4-OHE2) or 16-hydroxyestrone $(16 \alpha-\mathrm{OHE} 1)$ are present in the organism [15]. The anti-angiogenic properties of 2-MeOE2 have been demonstrated both in vivo and in vitro. It has also been shown that this metabolite has pro-apoptotic and antiproliferative properties in various cells in vitro [16]. In turn, the increased activity of 16a-hydroxylase, an enzyme involved in the formation of 16aOHE1, was observed in the population of women with breast cancer [12]. Still, no specific studies have been performed on $16 \alpha-\mathrm{OHE} 1$ in relation to the risk of ovarian cancer, and the potential role of estrogen metabolism in ovarian cancer has been found to be unclear.

Multidrug resistance (MDR) to chemotherapy is the major cause of treatment failure in ovarian cancer. MDR is a serious clinical problem that severely limits the success rate of chemotherapy in ovarian cancer treatment [17]. The earliest known mechanism of MDR is overexpression of the MDR1 gene and associated increased P-glycoprotein activity ( $\mathrm{P}$ $\mathrm{gp}$ ), which is responsible for the active removal of many structurally unrelated cytostatics from tumor cells. P-glycoprotein is a transmembrane protein that belongs to subfamily $\mathrm{B}$ of ATP-binding cassette transporters (ABC transporters). Ovarian neoplasms exhibit secondary multi-drug resistance with the participation of P-gp under the influence of cytostatic treatment [18].

The aim of our work was to evaluate the role of $17 \beta$-estradiol and its metabolites: 2-MeOE2 and 16 $\alpha$-OHE1 upon exposure to the metalloestrogen cadmium, a toxic environmental agent. The interactions of cadmium with estrogens and their influence on cell viability in malignant cisplatin-resistant ovarian cancer cells SKOV-3 were examined both in simultaneous action and in the pre-incubation model. These interactions are still poorly understood. There are no data in the literature on the influence of cadmium with estrogens 
on the pathogenesis of ovarian cancer, therefore it seems interesting to investigate their relationship. In connection with the dual role of estrogens, the question arises whether estrogens play a protective role in exposure to cadmium or whether the toxic effect is increased and what kind of interactions occur. Additionally, based on the calculated coefficient Combination Index (CI), the type of interaction between estrogens and cadmium was assessed. Since ovarian cancer is one of many cancers associated with multi-drug resistance, we also studied the effects of estrogens and cadmium on glycoprotein expression.

\section{Results}

\subsection{Cytotoxicity Evaluation of Single Compounds}

The study of single compounds on SKOV-3 cell viability was conducted to establish the cytotoxicity profile of compounds and optimize their concentrations to estimate their combined effect. The MTT test was performed after $24 \mathrm{~h}$ and $48 \mathrm{~h}$. Figure 1 shows SKOV-3 cell viability after the action of cadmium and estrogens.

a.

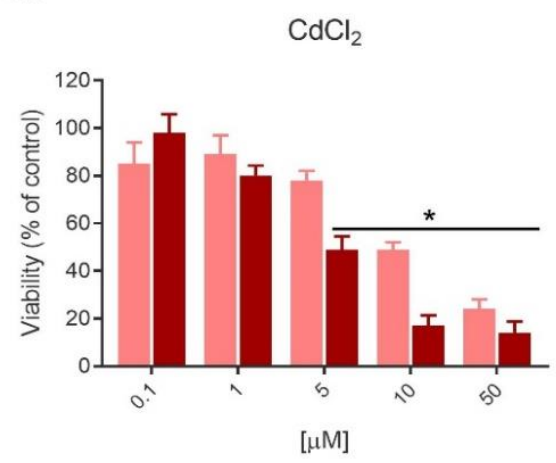

c.

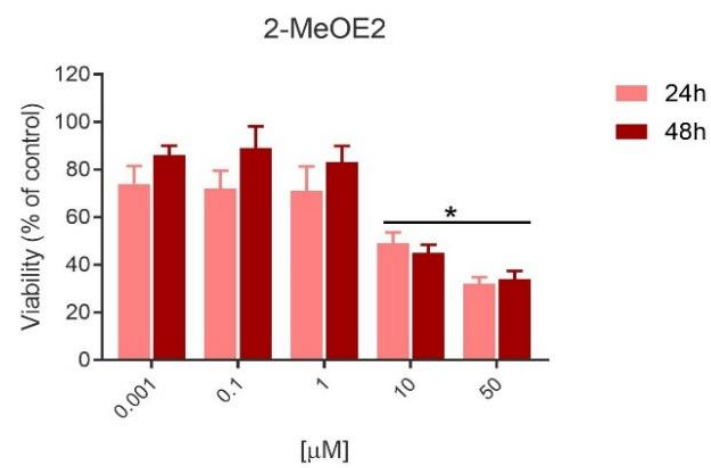

b.

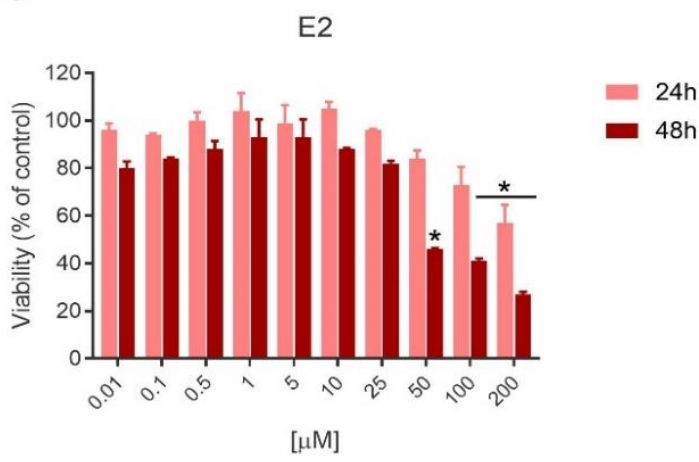

d.

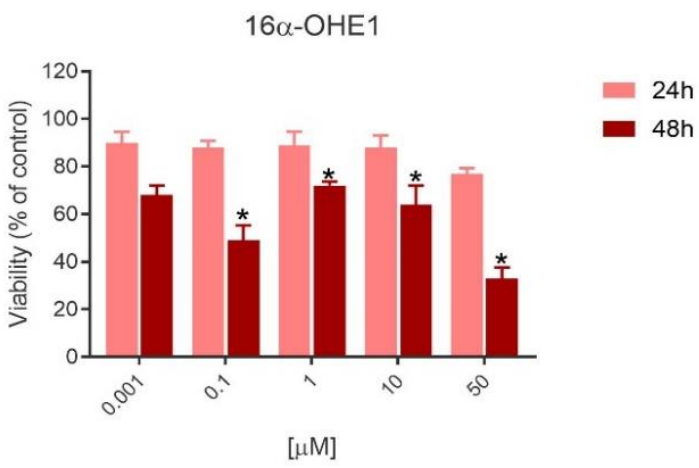

Figure 1. Changes in SKOV-3 viability after exposure to (a) $\mathrm{CdCl}_{2}$, (b) $\mathrm{E} 2$, (c) 2-MeOE2 and (d) $16 \alpha-$ OHE1, measured by MTT, after $24 \mathrm{~h}$ and $48 \mathrm{~h}$ (* statistically significant, $p<0.05)$.

In the conducted research, we observed a statistically significant decrease in SKOV-3 viability after cadmium exposure. The cytotoxicity of this compound after $48 \mathrm{~h}$ was more clearly indicated than after $24 \mathrm{~h}$. A significant decrease in viability was observed starting from $5 \mu \mathrm{M}$, while the highest dose of $\mathrm{Cd}(50 \mu \mathrm{M})$ decreased viability to $14 \%$. In high doses, 50-200 $\mu \mathrm{M}$, E2 caused a statistically significant decrease in viability, especially after $48 \mathrm{~h}$ incubation, up to $46 \%, 41 \%$ and $27 \%$, respectively. Estrogen metabolite exposure also caused a decrease in cell viability-2-MeOE2 led to a statistically significant decrease at two of its highest doses: 10 and $50 \mu \mathrm{M}$ after both incubation times. Mainly longer $48 \mathrm{~h}$ exposure to $16 \alpha-\mathrm{OHE} 1$ caused a statistically significant decrease in cell viability at $0.1 \mu \mathrm{M}$ and $50 \mu \mathrm{M}$. The effect of longer incubation time was especially important for exposure to $\mathrm{CdCl}_{2}, \mathrm{E} 2$ and $16 \alpha-\mathrm{OHE1}$, where viability after $48 \mathrm{~h}$ was much lower (Figure 1). 


\subsection{Evaluation of the Simultaneous Effect of E2 and Its Metabolites with} $\mathrm{CdCl}_{2}$-Interaction Study

Based on the results obtained and the literature data for the estrogen-cadmium interaction studies, the following concentrations were selected: for E2-0.01, 0.1, 10, 25, 50, and $200 \mu \mathrm{M}$; for 2-MeOE2 and for $16 \alpha-\mathrm{OHE} 1-1 \mathrm{nM}, 0.1,10$ and $50 \mu \mathrm{M}$. Moreover, the following doses were chosen for $\mathrm{CdCl}_{2}: 0.1,1,5,10$ and $50 \mu \mathrm{M}$. (Figures 2-4).

Table 1. Type of interaction after the combined effect of $\mathrm{E} 2$ and $\mathrm{CdCl}_{2}$ on SKOV-3 cells in the MTT test after $24 \mathrm{~h}$ and $48 \mathrm{~h}$ of incubation, using the CompuSyn program (S, synergism; $\mathrm{A}$, antagonism).

\begin{tabular}{ccccccccccc}
\hline & \multicolumn{1}{c}{ Incubation $\mathbf{2 4} \mathbf{h}$} & \multicolumn{7}{c}{ Incubation $\mathbf{4 8} \mathbf{h}$} \\
\cline { 2 - 12 } $\mathbf{E}_{2}[\mu \mathrm{M}]$ & $\mathbf{0 . 1}$ & $\mathbf{1}$ & $\mathbf{5}$ & $\mathbf{1 0}$ & $\mathbf{5 0}$ & $\mathbf{0 . 1}$ & $\mathbf{1}$ & $\mathbf{5}$ & $\mathbf{1 0}$ & $\mathbf{5 0}$ \\
\hline 0.01 & $\mathrm{~A}$ & $\mathrm{~S}$ & $\mathrm{~A}$ & $\mathrm{~A}$ & $\mathrm{~A}$ & $\mathrm{~S}$ & $\mathrm{~S}$ & $\mathrm{~A}$ & $\mathrm{~A}$ & $\mathrm{~A}$ \\
\hline 0.1 & $\mathrm{~A}$ & $\mathrm{~A}$ & $\mathrm{~A}$ & $\mathrm{~A}$ & $\mathrm{~A}$ & $\mathrm{~A}$ & $\mathrm{~A}$ & $\mathrm{~A}$ & $\mathrm{~A}$ & $\mathrm{~A}$ \\
\hline 10 & $\mathrm{~S}$ & $\mathrm{~S}$ & $\mathrm{~A}$ & $\mathrm{~A}$ & $\mathrm{~A}$ & $\mathrm{~A}$ & $\mathrm{~A}$ & $\mathrm{~A}$ & $\mathrm{~A}$ & $\mathrm{~A}$ \\
\hline 25 & $\mathrm{~A}$ & $\mathrm{~A}$ & $\mathrm{~S}$ & $\mathrm{~A}$ & $\mathrm{~A}$ & $\mathrm{~A}$ & $\mathrm{~A}$ & $\mathrm{~A}$ & $\mathrm{~A}$ & $\mathrm{~A}$ \\
\hline 50 & $\mathrm{~S}$ & $\mathrm{~A}$ & $\mathrm{~S}$ & $\mathrm{~A}$ & $\mathrm{~A}$ & $\mathrm{~A}$ & $\mathrm{~A}$ & $\mathrm{~A}$ & $\mathrm{~A}$ & $\mathrm{~A}$ \\
\hline 200 & $\mathrm{~S}$ & $\mathrm{~S}$ & $\mathrm{~S}$ & $\mathrm{~S}$ & $\mathrm{~A}$ & $\mathrm{~S}$ & $\mathrm{~S}$ & $\mathrm{~S}$ & $\mathrm{~A}$ & $\mathrm{~A}$ \\
\hline
\end{tabular}

a.

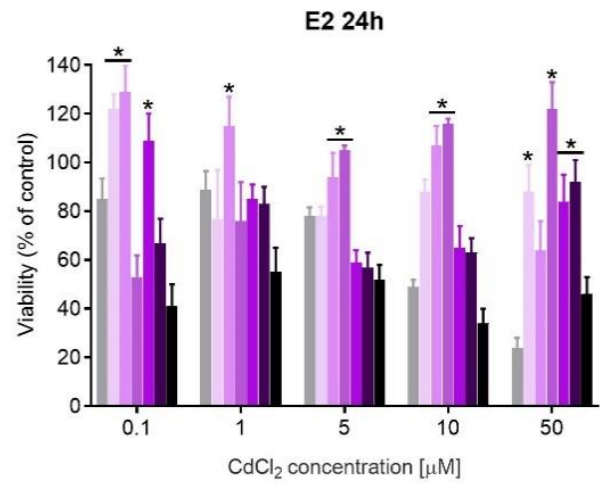

b.

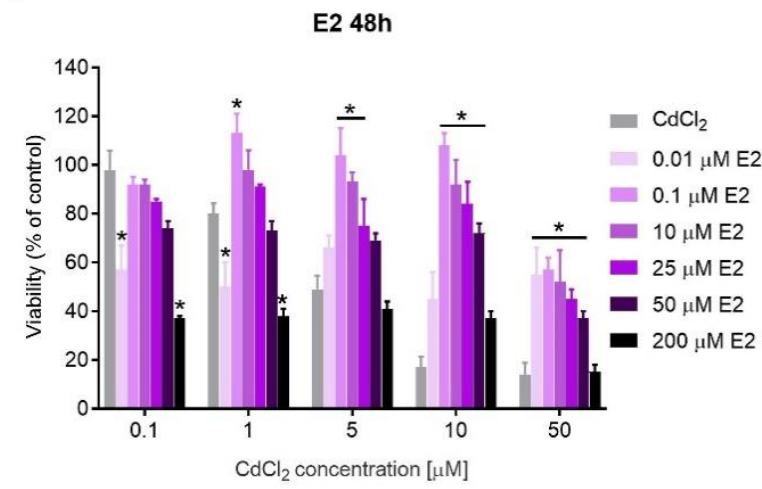

Figure 2. Changes in SKOV-3 viability after simultaneous effect of both $\mathrm{E} 2$ and $\mathrm{CdCl}_{2}$ measured by MTT after $24 \mathrm{~h}$ and $48 \mathrm{~h}$ against $\mathrm{CdCl}_{2}$ alone (* statistically significant, $p<0.05$ ). The type of interaction between estrogens and cadmium, calculated on the basis of the Combination Index (CI), is given in Tables $1-3$, respectively.

Table 2. Type of interaction after the combined effect of 2-MeOE2 and $\mathrm{CdCl}_{2}$ on SKOV-3 cells in the MTT test after $24 \mathrm{~h}$ and $48 \mathrm{~h}$ of incubation, using the CompuSyn program (S, synergism; A, antagonism).

\begin{tabular}{|c|c|c|c|c|c|c|c|c|c|c|}
\hline \multirow[b]{3}{*}{ 2-MeOE2 $[\mu \mathrm{M}]$} & \multicolumn{10}{|c|}{$\mathrm{CdCl}_{2}[\mu \mathrm{M}]$} \\
\hline & \multicolumn{5}{|c|}{ Incubation $24 \mathrm{~h}$} & \multicolumn{5}{|c|}{ Incubation $48 \mathrm{~h}$} \\
\hline & 0.1 & 1 & 5 & 10 & 50 & 0.1 & 1 & 5 & 10 & 50 \\
\hline 0.001 & $S$ & A & A & A & $S$ & $S$ & A & A & A & A \\
\hline 0.1 & $\mathrm{~A}$ & $\mathrm{~A}$ & $\mathrm{~A}$ & $\mathrm{~A}$ & $S$ & A & $S$ & A & $\mathrm{A}$ & A \\
\hline 10 & $\mathrm{~A}$ & $\mathrm{~A}$ & A & $\mathrm{A}$ & $\mathrm{A}$ & $S$ & $S$ & $S$ & A & $\mathrm{A}$ \\
\hline 50 & $\mathrm{~A}$ & $\mathrm{~A}$ & $\mathrm{~A}$ & $\mathrm{~A}$ & $\mathrm{~S}$ & $\mathrm{~A}$ & S & A & $\mathrm{A}$ & A \\
\hline
\end{tabular}


Table 3. Type of interaction after the combined effect of $16 \alpha-\mathrm{OHE} 1$ and $\mathrm{CdCl}_{2}$ on SKOV-3 cells in the MTT test after $24 \mathrm{~h}$ and $48 \mathrm{~h}$ of incubation, using the CompuSyn program (S, synergism; A, antagonism).

\begin{tabular}{|c|c|c|c|c|c|c|c|c|c|c|}
\hline \multirow[b]{3}{*}{$16 \alpha-\mathrm{OHE} 1[\mu \mathrm{M}]$} & \multicolumn{10}{|c|}{$\mathrm{CdCl}_{2}[\mu \mathrm{M}]$} \\
\hline & \multicolumn{5}{|c|}{ Incubation $24 \mathrm{~h}$} & \multicolumn{5}{|c|}{ Incubation $48 \mathrm{~h}$} \\
\hline & 0.1 & 1 & 5 & 10 & 50 & 0.1 & 1 & 5 & 10 & 50 \\
\hline 0.001 & $\mathrm{~S}$ & $\mathrm{~A}$ & A & $\mathrm{A}$ & $\mathrm{A}$ & A & $\mathrm{A}$ & A & $\mathrm{A}$ & A \\
\hline 0.1 & $S$ & $\mathrm{~A}$ & $\mathrm{~A}$ & $\mathrm{~A}$ & $\mathrm{~A}$ & $\mathrm{~A}$ & $\mathrm{~A}$ & $\mathrm{~A}$ & $\mathrm{~A}$ & $\mathrm{~A}$ \\
\hline 10 & $\mathrm{~S}$ & A & A & A & A & A & $\mathrm{A}$ & A & $\mathrm{A}$ & A \\
\hline 50 & $S$ & $S$ & A & A & $\mathrm{A}$ & $\mathrm{A}$ & $S$ & $S$ & A & A \\
\hline
\end{tabular}

a.

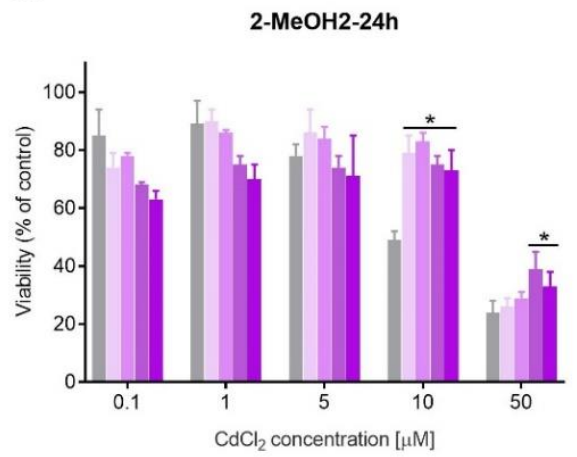

b.

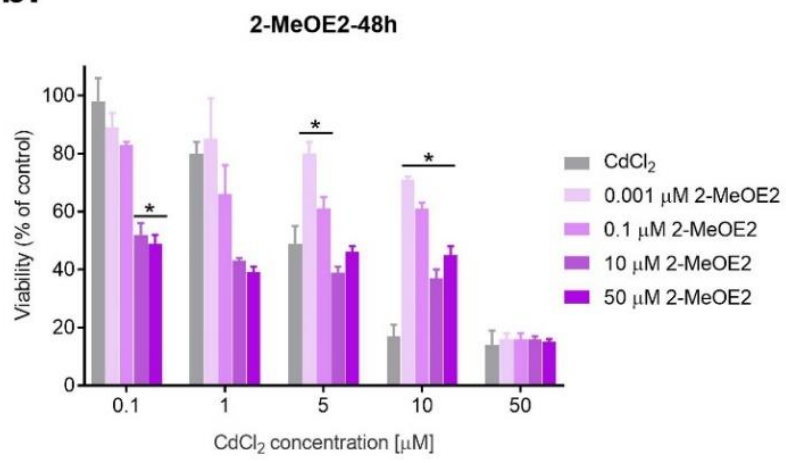

Figure 3. Changes in SKOV-3 viability after the simultaneous effect of both 2-MeOE2 and $\mathrm{CdCl}_{2}$ measured by MTT after $24 \mathrm{~h}$ and $48 \mathrm{~h}$ against $\mathrm{CdCl}_{2}$ alone ( ${ }^{*}$ statistically significant, $\left.p<0.05\right)$.

a.

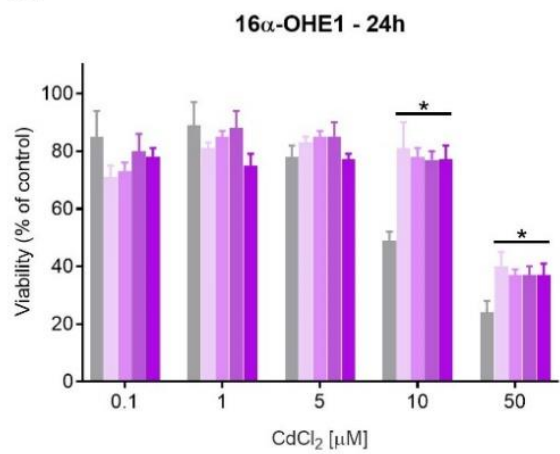

b.

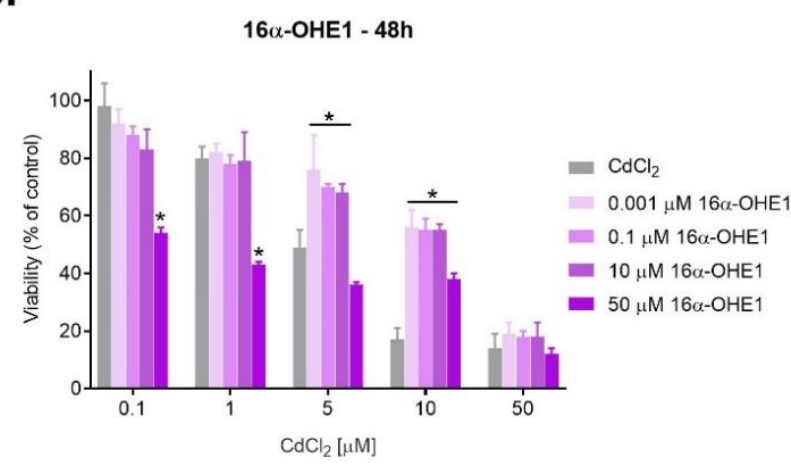

Figure 4. Changes in SKOV-3 viability after simultaneous effect of both $16 \alpha-\mathrm{OHE} 1$ and $\mathrm{CdCl}_{2}$ measured by MTT after $24 \mathrm{~h}$ and $48 \mathrm{~h}$ against $\mathrm{CdCl}_{2}$ alone ( ${ }^{*}$ statistically significant, $\left.p<0.05\right)$.

The nature of the interaction between $\mathrm{E} 2$ and $\mathrm{CdCl}_{2}$ depends to some extent on the time of incubation. Cases of synergism occur after $24 \mathrm{~h}$, while after a longer incubation of $48 \mathrm{~h}$, the dominant type of combined action is antagonism, especially after coexposure to lower doses of E2 (e.g., 0.1 and $10 \mu \mathrm{M}$ ), indicating a beneficial protective effect of E2 in SKOV-3 cells exposed to cadmium. Characteristically, high doses of E2 $(200 \mu \mathrm{M})$ do not protect against cadmium action. The majority of cadmium interactions with this concentration of E2 are of toxic synergy, and the viability is even lower than in cells exposed to $\mathrm{CdCl}_{2}$ alone. E2 at $50 \mu \mathrm{M}$ acted synergistically with lower doses of $\mathrm{CdCl}_{2}$. E2 $(25 \mu \mathrm{M})$ caused an antagonistic effect with both low and high doses of $\mathrm{CdCl}_{2}$, showing a protective action on SKOV-3 cells. E2 $(10 \mu \mathrm{M})$ was beneficial in cells exposed to Cd at 5-50 $\mu \mathrm{M}$. The 
results are consistent for both incubation times, with a slightly predominant antagonistic effect after a longer, $48 \mathrm{~h}$ incubation (Figure 2, Table 1).

As is the case for exposure to E2, antagonism prevails in combined action with 2MeOE2, with the beneficial effect of a shorter incubation time ( $24 \mathrm{~h})$, especially for lower concentrations of cadmium. A statistically significant increase in viability was observed for 2-MeOE2 at a concentration of $0.001 \mu \mathrm{M}(p<0.05)$. The highest dose of the tested metabolite $(50 \mu \mathrm{M})$ showed an antagonistic effect at most cadmium doses used in the experiment. However, 2-MeOE2 also had a protective effect, increasing the viability of ovarian cancer cells in a statistically significant manner, mainly with lower doses of metabolite $(p<0.05)$ (Table 2, Figure 3).

After incubation for $24 \mathrm{~h}$, marked antagonism was observed when exposed to the combined action of cadmium at a concentration of $10 \mu \mathrm{M}$ and $50 \mu \mathrm{M}$ with all concentrations of $16 \alpha$-OHE1 $(p<0.050)$. Synergism was also characteristic for the combined exposure of the highest concentration of the metabolite with low doses of cadmium $(0.1$ and $1.0 \mu \mathrm{M})$ $(p<0.05)$. Antagonism prevailed when SKOV-3 cells were exposed to a mixture of $16 \alpha-$ OHE1 and $\mathrm{CdCl}_{2}$ both after $24 \mathrm{~h}$ and $48 \mathrm{~h}$ of incubation (Figure 4, Table 3).

\subsection{Evaluation of the Effect of $\mathrm{CdCl}_{2}$ on SKOV-3 Cells after Pre-Incubation (24 hand 7 Days) with E2, 2-MeOE2 and $16 \alpha-O H E 1$}

In the following model of pre-incubation with estrogen, E2 or metabolites were added to cells at one concentration chosen during an earlier examination. The results are presented in Figure 5.

Based on preliminary research, non-toxic concentrations for $24 \mathrm{~h}$ and 7-day estrogen pre-incubation were selected: E2-0.01 $\mu \mathrm{M} ; 2 \mathrm{ME} 2-0.1 \mu \mathrm{M} ; 16 \alpha-\mathrm{OHE} 1-1 \mathrm{nM}$, to determine if estradiol or its metabolites could have a protective effect on SKOV-3 cells exposed to cadmium chloride. The effect of estrogens on cadmium-exposed SKOV-3 was examined by pre-incubating ovarian cancer cells with $\mathrm{E} 2$, then exposing them to $\mathrm{CdCl}_{2}$. The cells were pre-incubated with E2 at a concentration of $0.01 \mu \mathrm{M}$ for $24 \mathrm{~h}$ or 7 days, and viability was measured after a further $24 \mathrm{~h}$. When comparing $24 \mathrm{~h}$ and 7-day pre-incubation, many more beneficial effects were observed for $24 \mathrm{~h}$ pre-incubation (the highest cell viability). Seven-day pre-incubation was not as effective as $24 \mathrm{~h}$ pre-incubation, and in the case of high concentration of $\mathrm{CdCl}_{2}(50 \mu \mathrm{M})$, pre-incubation with E2 caused an increase in toxicity and up to $12 \%$ decrease in viability. The test conducted after a longer incubation of $48 \mathrm{~h}$ showed more pronounced differences in cell activity than after a shorter, $24 \mathrm{~h}$ incubation. Seven-day pre-incubation with 2-MeOE2 was the most beneficial. The protective effect of this metabolite on SKOV-3 cells pointed to a viability increase mainly after $24 \mathrm{~h}$ incubation. The cell viability test performed after 24 and after $48 \mathrm{~h}$ incubation indicated that $24 \mathrm{~h}$ preincubation resulted in no statistically significant change in viability in relation to cadmium alone or to the effect of this metabolite and metal co-exposure. Only the effect of the 7-day pre-incubation was very pronounced, especially during the shorter $24 \mathrm{~h}$ incubation. During the pre-incubation study with $16 \alpha$-OHE1, it was noticed that the test performed after $24 \mathrm{~h}$ of incubation showed no significant differences in viability, however, both $24 \mathrm{~h}$ and 7-day pre-incubation increased cell viability compared to cadmium alone. Much more significant differences were visible when the test was performed after $48 \mathrm{~h}$. In this case, a significant increase in viability was observed after $24 \mathrm{~h}$ of pre-incubation with $16 \alpha-\mathrm{OHE} 1$ as well as following 7-day pre-incubation. This increase was also statistically significant. In the case of co-exposure to $16 \alpha$-OHE1 and cadmium, the incubation time was observed to have a varied effect on the viability of SKOV-3. 
a.

E2 - $24 h$

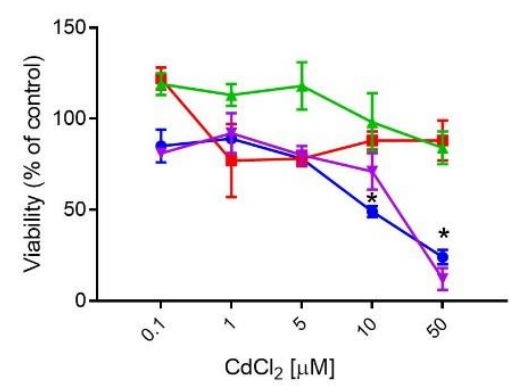

c.

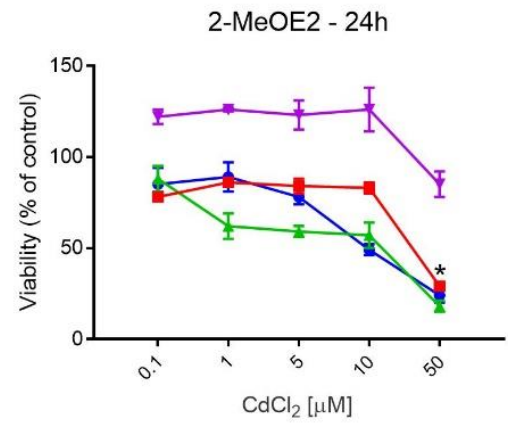

e.

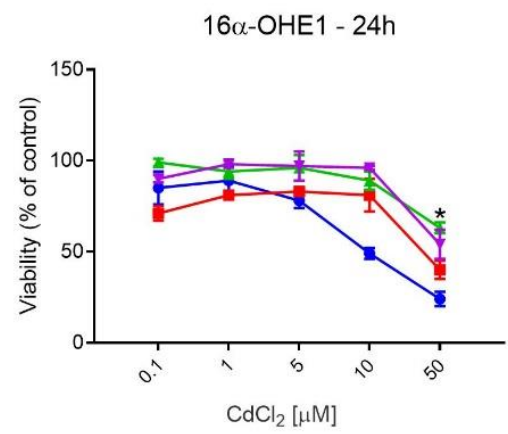

b.

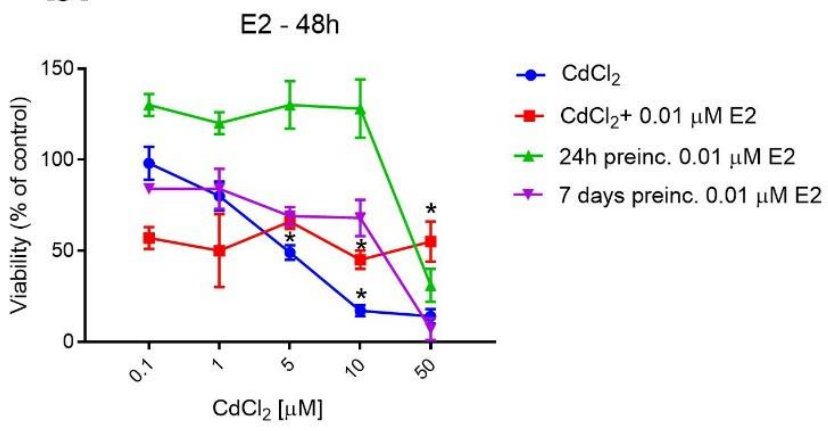

d.

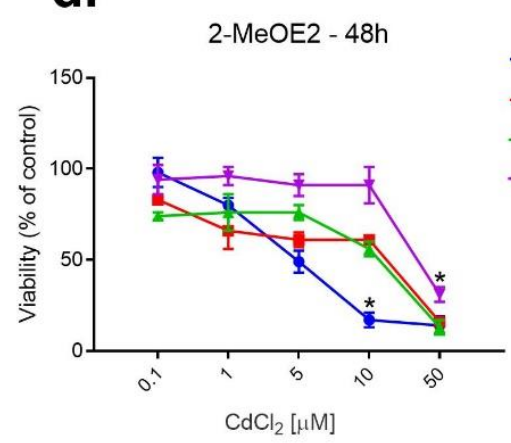

$\rightarrow \mathrm{CdCl}_{2}$

$-\mathrm{CdCl}_{2}+0.1 \mu \mathrm{M} 2-\mathrm{MeOE} 2$

- $24 \mathrm{~h}$ preinc. $0.1 \mu \mathrm{M} 2-\mathrm{MeOE} 2$

* 7 days preinc. $0.1 \mu \mathrm{M}$ 2-MeOE2

f.

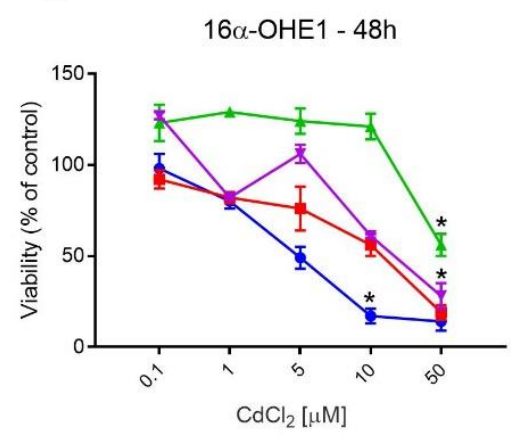

- $\mathrm{CdCl}_{2}$

$\_$24h preinc. $0.001 \mu \mathrm{M} 16 \alpha \mathrm{HyEstr}$

- 7 days preinc. $0.001 \mu \mathrm{M} 16 \alpha$ HyEstr

Figure 5. Changes in SKOV-3 viability after $24 \mathrm{~h}$ and 7 days of pre-incubation with E2 (a,b), 2-MeOE2 $(\mathbf{c}, \mathbf{d})$ and 16-OHE1 (e,f), and exposure to $\mathrm{CdCl}_{2}$ measured by MTT after $24 \mathrm{~h}$ and $48 \mathrm{~h}$. The figure also shows the combined action of the interaction of the respective estrogen with $\mathrm{CdCl}_{2}$ ( ${ }^{*}$ statistically significant, $p<0.05)$.

\subsection{Results of the Immunocytochemical P-gp Assay on the SKOV-3 Line after Exposure to} Estrogens and $\mathrm{CdCl}_{2}$

Table 4 shows the result of the action of E2 on P-gp expression. Cells exposed to E2 $(0.01 \mu \mathrm{M})$ had very low expression of P-gp $(3 \%)$, but at exposure to E2 $(200 \mu \mathrm{M})$, the intensity of the reaction was very high $(+++)$ and the percentage of stained cells was $90 \%$. Under the influence of the lowest concentration of $\mathrm{CdCl}_{2} 0.1 \mu \mathrm{M}, \mathrm{P}$-gp expression was $29 \%$ $(+)$. The increase in metalloestrogen concentration induced significant protein expression and high intensity of reaction (++/+++; $82 \%$ positive cells) at $50 \mu \mathrm{M} \mathrm{CdCl}_{2}$. The expression after exposure to 2-MeOE2 was much lower than for E2 and $\mathrm{CdCl}_{2}$ (3-48\%). For $16 \alpha-\mathrm{OHE} 1$, the reaction occurred only in cells exposed to the two highest concentrations $(10 \mu \mathrm{M}$ and $50 \mu \mathrm{M})$ with high intensity of reaction $(+++)$. The control sample was not exposed to the test compounds (Table 4 ). 
Table 4. Positive grading quantification of immunocytochemical staining of P-gp in the SKOV-3 line under the influence of estrogens and $\mathrm{CdCl}_{2}$. The number of stained cells was determined by counting 100 cells in 3 randomly selected fields. The intensity of the immunohistochemical staining was assessed as (-) negative (no reaction), $(+)$ weak, $(++)$ moderate and $(+++)$ strong.

\begin{tabular}{|c|c|c|}
\hline Compound & $\%$ of Stained Cells & Intensity of Reaction \\
\hline \multicolumn{3}{|c|}{$\mathrm{CdCl}_{2}[\mu \mathrm{M}]$} \\
\hline 0.1 & $29 \%$ & + \\
\hline 1 & $30 \%$ & $+/++$ \\
\hline 5 & $52 \%$ & $++/+++$ \\
\hline 10 & $47 \%$ & $+/++$ \\
\hline 50 & $82 \%$ & $++/+++$ \\
\hline \multicolumn{3}{|c|}{$\mathrm{E} 2[\mu \mathrm{M}]$} \\
\hline 0.01 & $3 \%$ & ++ \\
\hline 0.5 & $52 \%$ & ++ \\
\hline 5 & $45 \%$ & $+/++$ \\
\hline 25 & $74 \%$ & $++/+++$ \\
\hline 200 & $90 \%$ & +++ \\
\hline \multicolumn{3}{|c|}{ 2-MeOE2 [ $\mu \mathrm{M}]$} \\
\hline 0.001 & $14 \%$ & $+/++$ \\
\hline 0.1 & $8 \%$ & $+/+$ \\
\hline 1 & $6 \%$ & $+/+$ \\
\hline 10 & $3 \%$ & $++/+++$ \\
\hline 50 & $45 \%$ & $++/+++$ \\
\hline \multicolumn{3}{|c|}{$16 \alpha-O H E 1[\mu \mathrm{M}]$} \\
\hline 0.001 & $0 \%$ & - \\
\hline 0.1 & $0 \%$ & - \\
\hline 1 & $0 \%$ & - \\
\hline 10 & $44 \%$ & $++/+++$ \\
\hline 50 & $6 \%$ & $++/+++$ \\
\hline Control & $53 \%$ & ++ \\
\hline
\end{tabular}

The combined protocols $\left(\mathrm{E} 2+\mathrm{CdCl}_{2}\right)$ enhanced the intensity of reaction, especially for E2 $(10 \mu \mathrm{M})$. Exposure of cells to the action of $\mathrm{E} 2$ in conjunction with $\mathrm{CdCl}_{2}(50 \mu \mathrm{M})$ resulted in significant expression of P-gp in the range of 33-88\%, depending on the concentration of E2. Higher steroid concentrations resulted in a greater intensity of reaction $(++/+++)$ and a greater percentage of stained cells (Table 5).

Table 6 shows the combined effect of $2-\mathrm{MeOE} 2+\mathrm{CdCl}_{2}$ on P-gp expression. A different effect from $\mathrm{E} 2$ was observed, as the co-exposure of $2-\mathrm{MeOE} 2+\mathrm{CdCl}_{2}$ showed a very low percentage of stained cells (from $2 \%$ to $11 \%$ ) as well as a low intensity of the reaction $(+/++$ ). All results were below the control.

Table 7 shows the combined effect of $16 \alpha-\mathrm{OHE} 1$ with $\mathrm{CdCl}_{2}$ on P-gp expression. This combined protocol indicated that the percentage of stained cells was low (1-26\%), comparable to the effect of 2-MeOE2 in combination with $\mathrm{CdCl}_{2}$. The intensity of the reaction was mainly in the $+/++$ range, thus $16 \alpha-\mathrm{OHE}_{1}$, like $2-\mathrm{MeOE} 2$, did not increase $\mathrm{P}$ gp expression, although expression was increased to a slightly greater extent in $16 \alpha-\mathrm{OHE}_{1}$.

The degree of P-gp expression in ovarian cancer cells under the influence of the tested compounds presented in the Tables 4-7 reflects the microscopic results shown in Figure 6. 
Table 5. Positive grading quantification of immunocytochemical staining of P-gp in the SKOV-3 line under the influence of $\mathrm{E}_{2}$ with $\mathrm{CdCl}_{2}$. The number of stained cells was determined by counting 100 cells in 3 randomly selected fields. The intensity of the immunohistochemical staining was assessed as (-) negative (no reaction), $(+)$ weak, $(++)$ moderate and $(+++)$ strong.

\begin{tabular}{|c|c|c|c|c|c|}
\hline $\mathrm{CdCl}_{2}[\mu \mathrm{M}]$ & $\begin{array}{c}\% \text { of Stained } \\
\text { Cells }\end{array}$ & $\begin{array}{l}\text { Intensity of } \\
\text { Reaction }\end{array}$ & $\mathrm{CdCl}_{2}[\mu \mathrm{M}]$ & $\begin{array}{c}\% \text { of Stained } \\
\text { Cells }\end{array}$ & $\begin{array}{c}\text { Intensity of } \\
\text { Reaction }\end{array}$ \\
\hline \multicolumn{3}{|c|}{$E_{2} 0.01 \mu M$} & \multicolumn{3}{|c|}{$\mathrm{E}_{2} 25 \mu \mathrm{M}$} \\
\hline 0.1 & $21 \%$ & ++ & 0.1 & $49 \%$ & ++ \\
\hline 1 & $19 \%$ & $+/++$ & 1 & $31 \%$ & ++ \\
\hline 5 & $18 \%$ & ++ & 5 & $30 \%$ & ++ \\
\hline 10 & $27 \%$ & $++/+++$ & 10 & $36 \%$ & $++/+++$ \\
\hline 50 & $52 \%$ & $++/+++$ & 50 & $88 \%$ & +++ \\
\hline \multicolumn{3}{|c|}{$\mathrm{E}_{2} 0.1 \mu \mathrm{M}$} & \multicolumn{3}{|c|}{$\mathrm{E}_{2} 50 \mu \mathrm{M}$} \\
\hline 0.1 & $10 \%$ & $++/+++$ & 0.1 & $47 \%$ & ++ \\
\hline 1 & $10 \%$ & $++/+++$ & 1 & $28 \%$ & ++ \\
\hline 5 & $21 \%$ & ++ & 5 & $19 \%$ & $+/++$ \\
\hline 10 & $19 \%$ & ++ & 10 & $37 \%$ & ++ \\
\hline 50 & $43 \%$ & ++ & 50 & $26 \%$ & $+/++$ \\
\hline \multicolumn{3}{|c|}{$\mathrm{E}_{2} 10 \mu \mathrm{M}$} & \multicolumn{3}{|c|}{$\mathrm{E}_{2} 200 \mu \mathrm{M}$} \\
\hline 0,1 & $32 \%$ & +++ & 0,1 & $17 \%$ & + \\
\hline 1 & $31 \%$ & +++ & 1 & $48 \%$ & ++ \\
\hline 5 & $46 \%$ & +++ & 5 & $43 \%$ & ++ \\
\hline 10 & $43 \%$ & +++ & 10 & $47 \%$ & $++/+++$ \\
\hline 50 & $35 \%$ & +++ & 50 & $58 \%$ & +++ \\
\hline Control & $33 \%$ & $++/+++$ & Control & $33 \%$ & $++/+++$ \\
\hline
\end{tabular}

Table 6. Positive grading quantification of immunocytochemical staining of P-gp in the SKOV-3 line under the influence of 2-MeOE2 with $\mathrm{CdCl}_{2}$. The number of stained cells was determined by counting 100 cells in 3 randomly selected fields. The intensity of the immunohistochemical staining was assessed as (-) negative (no reaction), (+) weak, $(++)$ moderate and $(+++)$ strong.

\begin{tabular}{|c|c|c|c|c|c|}
\hline $\mathrm{CdCl}_{2}[\mu \mathrm{M}]$ & $\begin{array}{c}\% \text { of Stained } \\
\text { Cells }\end{array}$ & $\begin{array}{c}\text { Intensity of } \\
\text { Reaction }\end{array}$ & $\mathrm{CdCl}_{2}[\mu \mathrm{M}]$ & $\begin{array}{c}\% \text { of Stained } \\
\text { Cells }\end{array}$ & $\begin{array}{c}\text { Intensity of } \\
\text { Reaction }\end{array}$ \\
\hline \multicolumn{3}{|c|}{ 2-MeOE2 $0.001 \mu \mathrm{M}$} & \multicolumn{3}{|c|}{ 2-MeOE2 $10 \mu \mathrm{M}$} \\
\hline 0.1 & $2 \%$ & + & 0.1 & $2 \%$ & ++ \\
\hline 1 & $6 \%$ & + & 1 & $4 \%$ & ++ \\
\hline 5 & $11 \%$ & + & 5 & $7 \%$ & ++ \\
\hline 10 & $10 \%$ & + & 10 & $2 \%$ & ++ \\
\hline 50 & $9 \%$ & + & 50 & $11 \%$ & ++ \\
\hline \multicolumn{3}{|c|}{ 2-MeOE2 $0.1 \mu \mathrm{M}$} & \multicolumn{3}{|c|}{ 2-MeOE2 $50 \mu \mathrm{M}$} \\
\hline 0.1 & $10 \%$ & ++ & 0.1 & $5 \%$ & ++ \\
\hline 1 & $10 \%$ & ++ & 1 & $3 \%$ & ++ \\
\hline 5 & $5 \%$ & ++ & 5 & $5 \%$ & + \\
\hline 10 & $0 \%$ & - & 10 & $3 \%$ & ++ \\
\hline 50 & $0 \%$ & - & 50 & $9 \%$ & ++ \\
\hline Control & $33 \%$ & $++/+++$ & Control & $33 \%$ & $++/+++$ \\
\hline
\end{tabular}


Table 7. Positive grading quantification of immunocytochemical staining of P-gp in the SKOV-3 line under the influence of $16 \alpha$-OHE1 with $\mathrm{CdCl}_{2}$. The number of stained cells was determined by counting 100 cells in 3 randomly selected fields. The intensity of the immunohistochemical staining was assessed as (-) negative (no reaction), $(+)$ weak, $(++)$ moderate and $(+++)$ strong.

\begin{tabular}{|c|c|c|}
\hline $\mathrm{CdCl}_{2}[\mu \mathrm{M}]$ & $\%$ of Stained Cells & Intensity of Reaction \\
\hline \multicolumn{3}{|c|}{$16 \alpha$-OHE10.001 $\mu \mathrm{M}$} \\
\hline 0.1 & $1 \%$ & + \\
\hline 1 & $20 \%$ & ++ \\
\hline 5 & $25 \%$ & $+/++$ \\
\hline 10 & $11 \%$ & ++ \\
\hline 50 & $14 \%$ & $+/++$ \\
\hline \multicolumn{3}{|c|}{ 16 $\alpha$-OHE10.1 $\mu \mathrm{M}$} \\
\hline 0.1 & $0 \%$ & - \\
\hline 1 & $0 \%$ & - \\
\hline 5 & $16 \%$ & +++ \\
\hline 10 & $12 \%$ & $++/+++$ \\
\hline 50 & $21 \%$ & $++/+++$ \\
\hline \multicolumn{3}{|c|}{$16 \alpha$-OHE110 $\mu \mathrm{M}$} \\
\hline 0.1 & $11 \%$ & ++ \\
\hline 1 & $10 \%$ & $++/+++$ \\
\hline 5 & $14 \%$ & ++ \\
\hline 10 & $10 \%$ & + \\
\hline 50 & $26 \%$ & + \\
\hline Control & $33 \%$ & $++/+++$ \\
\hline
\end{tabular}
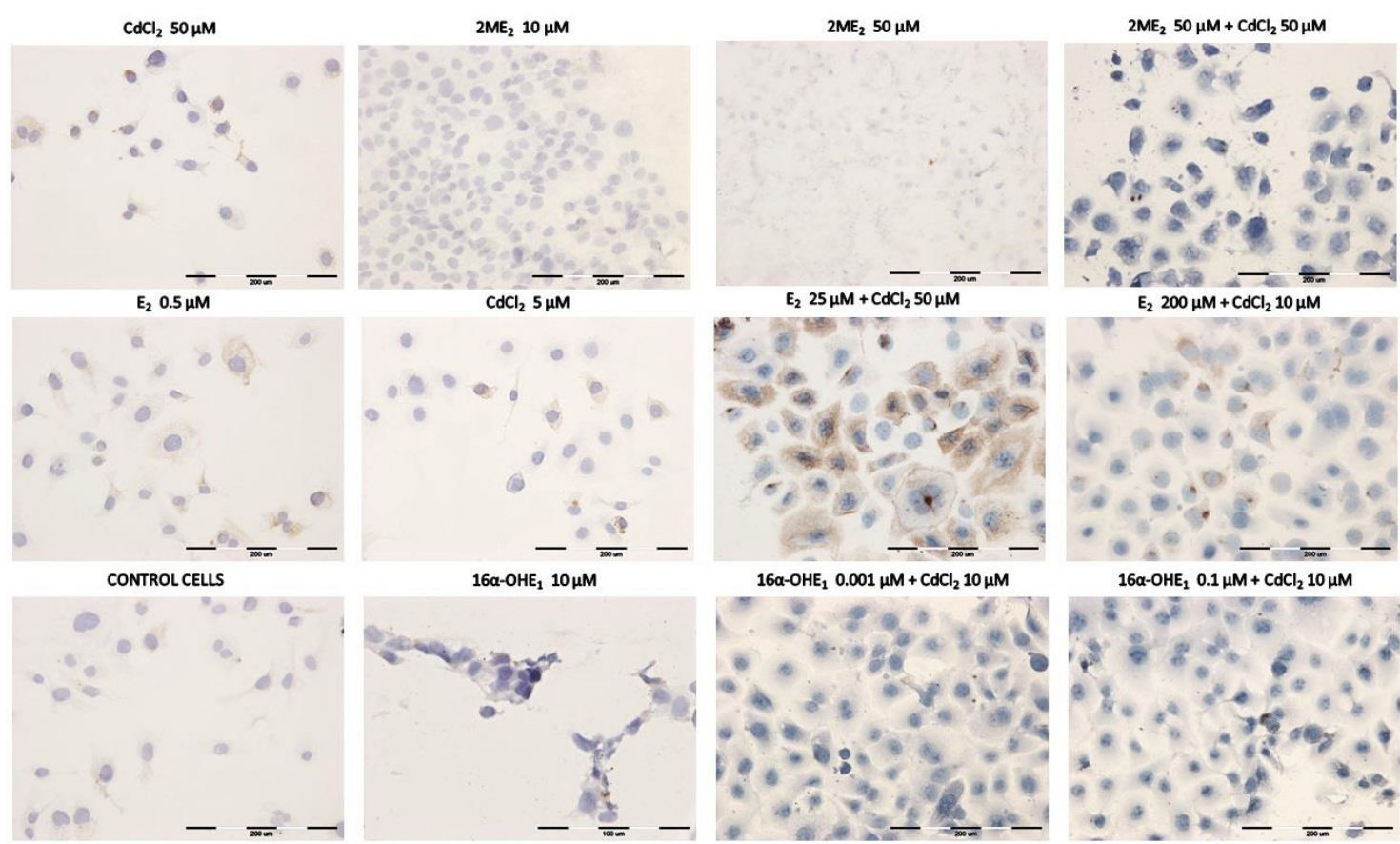

Figure 6. Immunoassayed reaction-exemplary expression results of P-glycoprotein in SKOV-3 ovarian cancer cells exposed to the single compounds and after exposure to the combined effects of estrogens and cadmium chloride. 


\section{Discussion}

Compounds capable of affecting the human hormone balance by binding to the estrogen receptor are widespread in the environment. Cadmium is a xenoestrogen, does not fulfill biological functions, and is a common environmental pollutant, found among others in tobacco and cigarette smoke. It is a human carcinogen recognized by IARC and, according to the literature data, may play a significant role in the pathogenesis of various cancers [19]. The exact pathogenesis of OCa is still not fully understood. Increasing morbidity and the high mortality caused by OCa, estrogen-dependent cancer, justify research into the impact of environmental xenoestrogens on estrogen-dependent processes [4]. Estrogens stimulate cell proliferation and division, showing indirect action through metabolites that may have a protective or pro-carcinogenic effect, depending on the biotransformation pathway. While 2-MeOE2 is a metabolite of E2 with recognized antitumor activity, $16 \alpha$-OHE1 is increasingly considered a compound with potential carcinogenic potential $[15,16]$. It seems important to understand the nature of the interaction between estrogens and cadmium, since estrogens are known for their protective functions and, on the other hand, the ability to induce carcinogenesis. Therefore, it is of interest whether estrogens have a protective effect on cells exposed to cadmium or if toxic synergy of action occurs.

An important aspect of many cancerous diseases, including ovarian cancer, is multidrug resistance. Many mechanisms are responsible for the formation of MDR; one of the best-known is the overexpression of the membrane transporter P-glycoprotein. Many tissues and organs are characterized by a high physiological concentration of this protein, which is responsible for removing harmful xenobiotics outside the cells. Secondary multidrug resistance with the participation of P-gp leads to the development of ovarian cancer. An excessive amount of this protein can be considered a multi-drug resistance marker [20]. In our examination, an attempt was made to assess whether estrogens may influence the expression of P-gp in ovarian carcinoma cells exposed to cadmium and, hence, to multidrug resistance. Currently, there is no research in the literature on this subject, which is why studies carried out as part of this work have an element of novelty.

The first stage of the study was the assessment of estrogens and cadmium toxicity on the SKOV-3 line, measured by the MTT test; the second stage involved a determination of P-gp expression under the influence of the tested compounds, measured by immunocytochemistry. The first stage of the study concerned the cytotoxicity of individual compounds, and then the combined action of estrogens with cadmium chloride was evaluated by two schemes described in the Methods section. The adverse effect of E2 on cell viability was noticeable for its high doses $(50-200 \mu \mathrm{M})$. The remaining E2 concentrations $(0.01-25 \mu \mathrm{M})$ were non-toxic. Although the effects of E2 on breast cancer cell lines have been studied, there is little research concerning metabolites. For example, Nunes et al. [21] conducted studies on the MCF-7 breast cancer cell line, in which they showed that E2 (100 nM) increases cell proliferation and has a cytoprotective effect. However, Seeger et al. [22] showed that, at physiological concentrations (0.1-10 nM), E2 enhances proliferation and decreases apoptosis of OVCAR-3 lines. Studies by Li et al. [23] also showed the antiapoptotic effects and increased proliferation in the same line by E2 (0.01-100 nM). Meanwhile, 2-MeOE2 is considered to be a metabolite with anticancer activity. Research carried out by Ding et al. [24] showed that 2-MeOE2 in combination with carboplatin significantly inhibited growth and induced apoptosis of SKOV-3 cells, showing a beneficial effect and sensitizing cells to cytostatics. Studies conducted by Saczko [25] have also shown that modifying photodynamic therapy by adding 2-MeOE2 significantly increases the effectiveness of the reaction and may eliminate cells of clear cell ovarian cancer (OvBH-1) by apoptosis. As was shown in our experiments, $16 \alpha$-OHE1 decreased cell viability, particularly after $48 \mathrm{~h}$ incubation. The effect of $16 \alpha-\mathrm{OHE} 1$ was clearly marked for high concentrations of the metabolite. There are only single studies concerning the effect of $16 \alpha-\mathrm{OHE} 1$ on ovarian cancer. An experiment carried out by Seeger et al. [22] indicates the anti-apoptotic and proliferative effect of $16 \alpha$-OHE1 $(0.01-10 \mathrm{nM})$ on ovarian cancer cells OVCAR-3. 
There are many papers on the influence of cadmium on the pathogenesis of cancers. A study by Zhang et al. [26] showed that exposure to cadmium may increase the risk of prostate cancer. A meta-analysis conducted by Lin et al. [27] shows that cadmium in the diet may increase the risk of breast cancer, and, according to studies by Jabłońska et al. [28], there is a correlation between increased cadmium concentration and the occurrence of breast cancer. There are only single experiments on the influence of cadmium on ovarian cancer. As a metalloestrogen, cadmium can affect estrogen-dependent processes. The ovarian membrane is rich in estrogen receptors, and there is a reasonable fear that this metal can affect the processes of cancer. The pathogenesis of ovarian cancer is still unexplained, so any research in this direction is important and will be helpful. Our research showed that cadmium chloride caused significant toxic effects on SKOV-3 cells, especially marked for concentrations of 5, 10 and $50 \mu \mathrm{M}$ after $48 \mathrm{~h}$ incubation. Cytotoxicity was dependent on the concentration of the metal, with an increase of the dose lowering viability, amounting to $49 \%, 17 \%, 14 \%$, respectively. Studies of the combined action of E2 with $\mathrm{CdCl}_{2}$ showed mostly a favorable protective effect of E2 on cadmium-exposed SKOV-3 cells after $24 \mathrm{~h}$ incubation. Analysis of the interaction performed using the CompuSyn program confirms its antagonism. The adverse toxic synergism was noted when combining the highest tested concentration of $\mathrm{E} 2(200 \mu \mathrm{M})$ with $\mathrm{CdCl}_{2}$, especially after $24 \mathrm{~h}$ incubation. The combined effect of E2 and $\mathrm{CdCl}_{2}$ after $48 \mathrm{~h}$ was advantageous and more clearly marked than $24 \mathrm{~h}$ incubation. From the above data, it can be concluded that, as manifested by reduced viability, high E2 concentration is toxic to the cancer cell line, which could be advantageous from the point of view of anti-cancer therapy with higher than physiological doses of estradiol. On the other hand, low doses of estradiol are protective in exposure to xenobiotics, so the protective effect of E2 in cadmium exposure may be suspect. The beneficial effect of 2MeOE2 in interaction with cadmium was observed when exposed to high concentrations of $\mathrm{CdCl}_{2}(10-50 \mu \mathrm{M})$, which correlated with results from the CompuSyn program, indicating favorable antagonism. At lower concentrations of $\mathrm{CdCl}_{2}(0.1-5 \mu \mathrm{M})$, there was synergy alternating with antagonism. The above results suggest that low, close to physiological $(0.001$ and $0.1 \mu \mathrm{M})$ concentrations of 2-MeOE2, especially at longer incubation, may protect cells exposed to toxic cadmium. In contrast, high concentrations of the metabolite are characterized by a large antiproliferative effect on ovarian cancer cells, which may be beneficial in anticancer therapy. After $24 \mathrm{~h}$ incubation, $16 \alpha$-OHE1 in interaction with $\mathrm{CdCl}_{2}$ showed a beneficial effect in SKOV-3 cells exposed to high doses of $\mathrm{CdCl}_{2}(5-50 \mu \mathrm{M})$, which corresponded to the results obtained from the interaction analysis (antagonism). At lower doses of $\mathrm{CdCl}_{2}$, estrogen showed toxic synergy. The high concentration of $16 \alpha$-OHE1 worked unfavorably in combination with Cd for SKOV-3 cells, reducing their activity. In the case of $\mathrm{CdCl}_{2}(5-10 \mu \mathrm{M})$, a beneficial antagonistic effect appeared.

In the second stage, the evaluation of the effect of $\mathrm{E} 2$ pre-incubation on $\mathrm{CdCl}_{2}$-induced damage in SKOV-3 cells, a clear beneficial effect of $24 \mathrm{~h}$ pre-incubation was observed. E2 protected SKOV-3 cells in the whole range of Cd concentrations. Seven-day pre-incubation was not as beneficial. The obtained result may prove the protective effect of estradiol in the case of cadmium-induced cytotoxicity, $24 \mathrm{~h}$ pre-incubation being sufficient to obtain the optimal effect. Seven-day pre-incubation with 2-MeOE2 produced positive results over the entire $\mathrm{CdCl}_{2}$ concentration range, both after 24 and $48 \mathrm{~h}$, while $24 \mathrm{~h}$ estrogen pre-incubation did not yield such beneficial effects. From the above studies, it can be concluded that 2-MeOE2 may have a protective effect on cadmium cell damage after the cells' long-term contact with estrogen and shorter exposure to the metal.

The next conducted part of the study involved the estimation of P-gp expression responsible for multidrug resistance. SKOV-3 ovarian cancer cells are characterized by P-gp overexpression. SKOV-3 cells exposed to E2 showed an increased expression of P-gp. Therefore, E2 in high doses has a negative effect on the cells; it increases defense processes in the cancer cell and may increase its multidrug resistance. The effect of low E2 concentrations would be beneficial in therapy. Similarly, in the case of $\mathrm{CdCl}_{2}$, the amount of P-gp in cells increases with the concentration of the metal. Cancer cells respond 
to toxic cadmium by increasing the expression of P-gp. In the case of chemotherapy, this response would involve not only cadmium, but also anti-cancer drugs. It can be concluded that MDR may increase after exposure to cadmium, and higher contamination of the environment may negatively affect anticancer treatment. Meanwhile, 2-MeOE2 significantly lowered the expression of P-gp. This effect could be very beneficial in reducing multidrug resistance and sensitizing cancer cells to therapy. The second metabolite tested, $16 \alpha$-OHE1, did not give such unambiguous results. While it seems that it can also reduce the expression of P-gp in tumor cells, it does so in a smaller range of concentrations. Using the immunocytochemistry assay, the expression of P-gp after the combined application of estrogens and $\mathrm{CdCl}_{2}$ was evaluated. The role of $\mathrm{E} 2$ in such exposure has been shown to be ambiguous. Low $\mathrm{E} 2$ concentrations produced a positive effect $(0.01-0.1 \mu \mathrm{M})$, reducing the expression of P-gp in cells induced by low concentrations of $\mathrm{CdCl}_{2}(0.1-10 \mu \mathrm{M})$, which can be considered as a reduction in cell sensitivity to toxic compounds and a beneficial effect in the context of anticancer therapies. In exposure to $\mathrm{CdCl}_{2}, 2 \mathrm{ME} 2$ still had a positive effect, because the expression of P-gp was significantly reduced, regardless of the concentration of $\mathrm{CdCl}_{2}$. The significant reduction in P-gp expression caused by $16 \alpha$-OHE1 would suggest a beneficial effect of this metabolite on tumor cells treated with xenobiotics, including anticancer drugs. Scientific articles indicate that multi-drug resistance of tumors is a serious problem that is still under investigation. An experiment conducted by Bradley et al. [29] showed an increasing overexpression of P-gp in SKOV-3 cells due to increasing concentrations of vinca alkaloids. In turn, Yang et al. [30] observed that SKOV-3 cell lines were characterized by increased expression of P-gp under the influence of cisplatin. The studies also showed that verapamil sensitized the cells of the test line to doxorubicin. There are many studies on the breakdown of multidrug resistance to increase the effectiveness of anticancer therapies. A study by Patel et al. [31] showed that coadministration of the $\mathrm{P}$-gp inhibitor and paclitaxel into the tumor made it sensitive to cytostatics, indicating a promising way to overcome MDR.

To summarize, E2 had no toxic effect on SKOV-3 in low concentrations, while high concentrations of this hormone $(50-200 \mu \mathrm{M})$ were cytotoxic, which may prove beneficial from the point of view of anti-cancer therapy. In the dose range of $0.001-1 \mu \mathrm{M}, 2-\mathrm{MeOE} 2$ did not show any toxic effects, and at concentrations of 10-50 $\mu \mathrm{M}$ it significantly reduced the viability of SKOV-3. In contrast, $16 \alpha-\mathrm{OHE} 1$ showed toxic effects after longer incubation. The interaction study demonstrated the antagonistic effect of E2 on cadmium-induced cell damage. Meanwhile, 2-MeOE2 showed a weaker protective effect in combination with $\mathrm{CdCl}_{2}$ than E2. There were two types of interactions: toxic synergism and favorable antagonism, depending on the dose of the metabolite. Considering the effect of estrogen pre-incubation, a protective effect of $24 \mathrm{~h}$ estradiol incubation was noticed, while for 2MeOE2, a longer, 7-day pre-incubation period was more beneficial. E2 and cadmium caused increased expression of P-gp in SKOV-3 cells, i.e., increased MDR, which may negatively affect anticancer treatment. Meanwhile, 2-MeOE2 significantly reduced the expression of P-gp with a potentially beneficial effect in the prevention of MDR. With simultaneous exposure to estrogen and cadmium, SKOV-3 cells were characterized by decreased expression of P-gp. The obtained results constitute an interesting starting point for further research in this area and for the analysis of pathways involved in both tumor progression and cancer cell death as a result of the applied therapies.

\section{Material and Methods}

\subsection{Cell Culture}

The research was conducted on the ovarian cell line SKOV-3. The cell line was obtained from the Department of Immunology, Center of Biostructure Research at Medical University of Warsaw as part of scientific cooperation, purchased in ATCC, and validated negatively according to mycoplasma. Line authentication was performed using a PCRbased technique that compares multiple short tandem repeat (STR) markers between two or more cell genomes with MycoBlue (Vazyme). The cultures were maintained in $37^{\circ} \mathrm{C}$ 
and high humidity in the Steri-Cult ${ }^{\circledR}$ Automated $\mathrm{CO}_{2}$ Incubator (Thermo Scientific, Alab, Poland). Dulbecco's Modified Eagle's Medium (DMEM) with a glucose concentration of $4500 \mathrm{mg} / \mathrm{L}$ (Sigma-Aldrich, Poznań, Poland), supplemented with fetal bovine albumin $(10 \%)$ (FBS, Sigma-Aldrich, Poland) and 1\% antibiotic solution containing 10,000 units penicillin and $10 \mathrm{mg}$ streptomycin/mL (Sigma Aldrich, St. Louis, MO, USA) were used as a culture medium.

\subsection{Compounds}

The estrogens E2, 2-MeOE2, $16 \alpha$-OHE1 and cadmium chloride $\left(\mathrm{CdCl}_{2}\right)$ were used as a source of cadmium ions for this study. The list of compounds was presented in Table 8 . Estrogen solutions were prepared in $96 \%$ ethanol, while distilled water was used for $\mathrm{CdCl}_{2}$ (Table 8).

Table 8. List of compounds used in the experiments.

$\begin{gathered}\text { Name of Compound } \\ \text { and Manufacturer }\end{gathered}$
$\begin{gathered}\text { 16 } \alpha-O H E 1 \\ \text { STERALOIDS }\end{gathered}$
$\begin{gathered}\text { 2-MeOE2 } \\ \text { Cadmium chloride }\end{gathered}$

\subsection{Cytotoxicity Assay of Individual Estrogens and $\mathrm{CdCl}_{2}$}

Cell viability was evaluated by MTT assay according to the manufacturer protocol (Sigma-Aldrich). First, cells were incubated with estrogens (E2, 2-MeOE2, 16 $\alpha$-OHE1) or $\mathrm{CdCl}_{2}$ independently (separately) to evaluate the cytotoxicity of these compounds to SKOV-3 cells. The following concentrations of compounds were used: E2-0.01, 0.1, 0.5, $1.0,5.0,10.0,25.0,50,100.0$ and $200.0 \mu \mathrm{M} ; 2-\mathrm{MeOE} 2$ and $16 \alpha$-OHE1-0.001, 0.1, 1.0, 10.0, $50 \mu \mathrm{M} ; \mathrm{CdCl}_{2}-0.1,1.0,5.0,10.0$ and $50.0 \mu \mathrm{M}$. After separate exposure, concentrations were chosen for further studies of the combined effect of $\mathrm{E} 2$ or its metabolites with $\mathrm{CdCl}_{2}$ on the ovarian cancer cell line. To determine cytotoxicity, cells were seeded into 96-well culture plates at a concentration of $5 \times 10^{4}$ cell/well (Nunc, NunclonTM Surface, Biokom, Poland) according to the previously described method [32]. All tests were performed in triplicates.

\subsection{Combined Effect of Cadmium with Estrogens}

In the first model of combined effect-simultaneous action, single estrogens and $\mathrm{Cd}$ ions were added to the cell culture simultaneously and incubated for $24 \mathrm{~h}$ and $48 \mathrm{~h}$ at $37^{\circ} \mathrm{C}$. The dose selection for the interaction study was dictated by the study of individual compounds: for E2-0.01, 0.1, 10.0, 25.0, 50.0 and $200 \mu \mathrm{M}$; for 2-MeOE2 and 16 $\alpha$-OHE1-0.001, 0.1, 10.0 and $50 \mu \mathrm{M}$; for $\mathrm{Cd}-0.1,1.0,5.0,10.0$ and $50.0 \mu \mathrm{M}$. 
To estimate the type of interaction, the combination index (CI) was calculated by CompuSyn software. The CI was calculated for the IC50 obtained during an in vitro experiment (data not shown). The results were interpreted as follows: $\mathrm{CI}=1$ indicates the additive effect of the test substances on the viability of ovarian cancer cells; $\mathrm{CI}<1$ indicates synergy $(S)$ between the compounds used for the study; while $C I>1$ indicates the antagonism (A) that occurs between them [33].

In the model of pre-incubation, first estrogen was added in one selected dose: E2$0.01 \mu \mathrm{M} ; 2-\mathrm{MeOE} 2-0.1 \mu \mathrm{M} ; 16 \alpha$-OHE1 $-0.001 \mu \mathrm{M}$. Next, $\mathrm{CdCl}_{2}$ was added in the following doses: $0.1,1.0,5.0,10.0$ and $50.0 \mu \mathrm{M}$. The number of cells used for all experiments was the same as for simultaneous action. In the first step, estrogen was added to the culture medium and the cells were pre-incubated in the culture flask for $24 \mathrm{~h}$ or 7 days (with a million cells per flask). Then, cells were seeded in $5 \times 10^{4}$ cell/well assay plates and incubated for $24 \mathrm{~h}$ to stick the cells to the wells. The cadmium solution was then added to the culture medium in appropriate concentrations. The plates were incubated for $24 \mathrm{~h}$ or $48 \mathrm{~h}$, respectively. Then, the cytotoxicity test was used. All tests were performed in triplicates.

\subsection{P-gp Estimation-Immunocytochemical Staining}

Additionally, the expression of P-gp was investigated in SKOV-3 ovarian cancer cells. This study assessed the expression of P-gp in SKOV-3 ovarian cancer cells exposed to the single compounds and after exposure to the combined effects of estrogens and cadmium chloride. Cells were plated on 10-well slides (Thermo Scientific, Waltham, MA, USA) and incubated for $24 \mathrm{~h}$. The slides were then rinsed with PBS and fixed with $4 \%$ paraformaldehyde. The next step was to perform an immunocytochemical test with the Expose Mouse and Rabbit Specific HRP/DAB Detection IHC kit (Abcam, Waltham, MA, USA, ab80436). The kit contained the following reagents: Mouse Determination Reagent, HRP Conjugate, DAB Substrate, DAB Chromogen, Hydrogen Peroxide Block.

Briefly, after washing with PBS $(3 \times 5 \mathrm{~min})$, peroxidase activity was blocked by $30 \mathrm{~min}$ incubation with $1 \% \mathrm{H}_{2} \mathrm{O}_{2}$; then, samples were permeabilized by incubation with $1 \%$ Triton X-100 (Sigma, Poland) in PBS (LabEmpire, Rzeszów, Poland). The cells were then incubated with the selected antibodies overnight at $4{ }^{\circ} \mathrm{C}$. Primary antibodies (diluted 1:200, purchased from Abcam, USA) were used: anti-Aquaporin 4 [4/18] antibody-mouse monoclonal IgG (Abcam, USA ab9512) and anti-VDAC1/Porin antibody—rabbit polyclonal IgG (ab34726, Abcam). Cells were incubated with a secondary horseradish peroxidase (HRP) conjugated antibody. The samples were then incubated with a mixture of diaminobenzidine- $\mathrm{H} 2 \mathrm{O} 2$ to show the HRP marker and were counterstained with hematoxylin (Roth, Poland) for 3 min. After dehydration in a gradient of ethanol (Chempur, Rzeszów, Poland) and xylene (Chempur, Poland), the microscope slides were covered with DPX (Aqua-Med ZpamKolasa, Poland). A vertical microscope (Olympus BX53, Warszawa, Poland) was used for sampling. The number of stained cells was determined by counting 100 cells in 3 randomly selected fields. First, the staining of the cells was tested. The percentage of stained cells was shown in the table, after which the intensity of the staining was estimated. The intensity of the immunohistochemical staining was assessed as (-) negative (no reaction), $(+)$ weak, $(++)$ moderate and $(+++)$ strong [34].

\subsection{Statistical Analysis}

All values were expressed as mean $\pm \mathrm{SD}$. The normality of the distribution was assessed by the Lilliefors test. Differences between groups were assessed by one-way analysis of variance (ANOVA), which compares three or more unmatched groups, based on the assumption that the populations are Gaussian. Analysis was performed using the GraphPad Prism 7 software (GraphPad Software-DMW Communication, San Diego, CA, USA, CA). Values of $p<0.05$ were considered significant. Dose-effect analysis of the combination treatment was calculated using the combination index (CI) by CompuSyn software [33]. 
In conclusion, the protective effect of estrogens may play a significant role in the pathogenesis of $\mathrm{OCa}$, especially in environmental exposure to cadmium compounds. According to the research conducted as part of this work, the examined compounds may show a positive effect on cells exposed to cadmium, protecting them from damage. On the other hand, given the results, hormones can reduce the effectiveness of chemotherapy. Similarly, in the case of MDR, the tested metabolites may have a positive effect on the effects of treatment, but there is also a risk of limiting the effect of estradiol in the presence of environmental pollutants, which undoubtedly include cadmium.

\begin{abstract}
Author Contributions: E.S., J.K. and J.S. conceived and planned the project. E.S., M.S. and J.K. contributed to preparing the samples and conducting the experiments. E.S., M.S., J.S. and B.S. collected data and analyzed results. E.S., J.K. and M.S. interpreted the results. E.S, J.S., J.K. and A.P. prepared the manuscript and helped to shape the analysis and manuscript through critical feedback. E.S. and A.P critically revised the final version of the manuscript. E.S. sent the manuscript and corresponded with the editor. All authors have read and agreed to the published version of the manuscript.
\end{abstract}

Funding: Task subsidy of the Medical University of Wrocław No. SUBZ.D150.22.043.

Conflicts of Interest: The authors declare no conflict of interest.

\title{
References
}

1. Genchi, G.; Sinicropi, M.S.; Lauria, G.; Carocci, A.; Catalano, A. The Effects of Cadmium Toxicity. Int. J. Environ. Res. Public Health 2020, 17, 3782. [CrossRef] [PubMed]

2. Fatima, G.; Raza, A.M.; Hadi, N.; Nigam, N.; Mahd, A.A. Cadmium in human diseases: It's more than just a mere metal. Ind. J. Clin. Biochem. 2019, 34, 371-378. [CrossRef] [PubMed]

3. Scsukov, S.; Rollerova, E.; Bujnakova Mlynarcikova, A. Impact of endocrine disrupting chemicals on onset and development of female reproductive disorders and hormone-related cancer. Reprod. Biol. 2016, 16, 243-254. [CrossRef] [PubMed]

4. Adams, S.; Passarelli, M.; Newcomb, P. Cadmium exposure and cancer mortality in the Third National Health and Nutrition Examination Survey cohort. Occup. Environ. Med. 2012, 69, 153-156. [CrossRef]

5. García-Perez, J.; Lope, V.; Lopez-Abente, G.; Gonzalez-Sanchez, M.; Fernandez-Navarro, P. Ovarian cancer mortality and industrial pollution. Environ. Pollut. 2015, 205, 103-110. [CrossRef] [PubMed]

6. Stewart, C.; Ralyea, C.; Lockwood, S. Ovarian Cancer: An Integrated Review. Semin. Oncol. Nurs. 2019, 35, 151-156. [CrossRef] [PubMed]

7. Reid, B.; Permuth, J.; Sellers, T. Epidemiology of ovarian cancer: A review. Cancer Biol. Med. 2017, 14, 9-32.

8. Mungenast, F.; Thalhammer, T. Estrogen biosynthesis and action in ovarian cancer. Front. Endocrinol. 2014, 5, 192. [CrossRef] [PubMed]

9. Temkin, S.M.; Mallen, A.; Bellavance, E.; Rubinsak, L.; Wenham, R.M. The role of menopausal hormone therapy in women with or at risk of ovarian and breast cancers: Misconceptions and current directions. Cancer 2019, 125, 499-514. [CrossRef]

10. Brown, S.B.; Hankinson, S.E. Endogenous estrogens and the risk of breast, endometrial, and ovarian cancers. Steroids 2015, 99, 8-10. [CrossRef]

11. Park, S.H.; Cheung, L.W.; Wong, A.S.; Leung, P.C. Estrogen regulates snail and slug in the down-regulation of E-cadherin and induces metastatic potential of ovarian cancer cells through estrogen receptor alpha. Mol. Endocrinol. 2008, 22, 2085-2098. [CrossRef] [PubMed]

12. Park, S.H.; Kim, K.Y.; An, B.S.; Choi, J.H.; Jeung, E.B.; Leung, P.C.; Choi, K.C. Cell growth of ovarian cancer cells is stimulated by xenoestrogens through an estrogen-dependent pathway, but their stimulation of cell growth appears not to be involved in the activation of the mitogen-activated protein kinases ERK-1 and p38. J. Reprod. Dev. 2009, 55, 23-29. [CrossRef] [PubMed]

13. Martin, B.M.; Reiter, R.; Pham, T.; Avellanet, J.C.; Lahm, M.; Pentecost, E.; Pratap, K.; Gilmore, B.A.; Divekar, S.; Dagata, R.S.; et al. Estrogen-like activity of metals in MCF-7 breast cancer cells. Endocrinology 2003, 144, 2425-2436. [CrossRef] [PubMed]

14. Zahid, M.; Beseler, C.L.; Hall, J.B.; LeVan, T.; Cavalieri, E.L.; Rogan, E.G. Unbalanced estrogen metabolism in ovarian cancer. Int. J. Cancer 2014, 134, 2414-2423. [CrossRef]

15. Samvat, H.; Kurzer, M. Estrogen Metabolism and Breast Cancer. Cancer Lett. 2015, 356, 231-243. [CrossRef]

16. Parada-Bustamante, A.; Valencia, C.; Reuquén, P.; Díaz, P.; Rincón-Rodriguez, R.; Orihuela, P. Role of 2-methoxyestradiol, an Endogenous Estrogen Metabolite, in Health and Disease. Mini-Rev. Med. Chem. 2015, 15, 427-438. [CrossRef]

17. Chandra, A.; Pius, C.; Nabeel, M.; Nair, M.; Vishwanatha, J.K.; Ahmad, S.; Basha, R. Ovarian cancer: Current status and strategies for improving therapeutic outcomes. Cancer Med. 2019, 8, 7018-7031. [CrossRef]

18. Wang, Y.; Chen, G.; Dai, F.; Zhang, L.; Yuan, M.; Yang, D.; Liu, S.; Cheng, Y. miR-21 Induces Chemoresistance in Ovarian Cancer Cells via Mediating the Expression and Interaction of CD44v6 and P-gp. Onco Targets Ther. 2021, 14, 325-336. [CrossRef]

19. Mulware, S.J. Trace elements and carcinogenicity: A subject in review. Biotech 2013, 3, 85-96. [CrossRef] 
20. Jia, Y.; Sun, S.; Gao, X.; Cui, X. Expression levels of TUBB3, ERCC1 and P-gp in ovarian cancer tissues and adjacent normal tissues and their clinical significance. J. Buon. 2018, 23, 1390-1395.

21. Nunes, C.; Silva, C.; Correia-Banco, A.; Martel, F. Lack of effect of the procancerogenic 17B-estradiol on nutrient uptake by the MCF-7 breast cancer line. Biomed. Farmacother. 2017, 90, 287-294. [CrossRef] [PubMed]

22. Seeger, H.; Wallwiener, D.; Kraemer, E.; Mueck, A.O. Estradiol metabolites are potent mitogenic substances for human ovarian cancer cells. Eur. J. Gynaecol. Oncol. 2005, 26, 383-385. [PubMed]

23. Li, H.; Zhao, Y.; Li, Y.; Dai, C.; Jobe, S.; Yang, X.; Li, X.; Patankar, M.; Magness, R.; Zheng, J. 17 $\beta$-,tradiol and Its Metabolites Stimulate Cell Proliferation and Antagonize Ascorbic Acid-Suppressed Cell Proliferation in Human Ovarian Cancer Cells. Reprod. Sci. 2014, 21, 102-111. [CrossRef] [PubMed]

24. Ding, L.; Wang, X.-Q.; Zhang, J.; Mu, Z.-L.; Zhou, X.-X.; Liu, P.-S. Underlying mechanism of 2-methoxyestradiol induced apoptosis and growth arrest in SKOV3 human ovarian cancer cells. Eur. Rev. Med. Pharmacol. Sci. 2015, 19, 2084-2090. [PubMed]

25. Saczko, J.; Choromańska, A.; Rembiałkowska, N.; Dubińska-Magiera, M.; Bednarz-Misa, I.; Bar, J.; Marcinkowska, A.; Kulbacka, J Oxidative modification induced by photodynamic therapy with Photofrin ${ }^{\circledR} \mathrm{II}$ and 2-methoxyestradiol in human ovarian clear carcinoma (OvBH-1) and human breast adenocarcinoma (MCF-7) cells. Biomed. Pharmacother. 2015, 71, 30-36. [CrossRef] [PubMed]

26. Zhang, L.; Zhu, Y.; Hao, R.; Shao, M.; Luo, Y. Cadmium Levels in Tissue and Plasma as a Risk Factor for Prostate Carcinoma: A Meta-Analysis. Biol. Trace Elem. Res. 2016, 172, 86-92. [CrossRef]

27. Lin, J.; Zhang, F.; Lei, Y. Dietary intake and urinary level of cadmium and breast cancer risk: A meta-analysis. Cancer Epidemiol. 2016, 42, 101-107. [CrossRef]

28. Jabłońska, E.; Socha, K.; Reszka, E.; Wieczorek, E.; Skokowski, J.; Kalinowski, L.; Fendler, W.; Seroczyńska, B.; Woźniak, M.; Borawska, M.H.; et al. Cadmium, arsenic, selenium and iron- Implications for tumor progression in breast cancer. Environ. Toxicol. Phar. 2017, 53, 151-157. [CrossRef]

29. Bradley, G.; Naik, M.; Ling, V. P-Glycoprotein Expression in Multidrug-resistant Human Ovarian Carcinoma Cell Lines. Cancer Res. 1989, 49, 2790-2796.

30. Yang, X.; Pagé, M. P-glycoprotein expression in ovarian cancer cell line following treatment with cisplatin. Oncol. Res. 1995, 7, 619-624.

31. Patel, N.R.; Rathi, A.; Mongayt, D.; Torchilin, V.P. Reversal of multidrug resistance by co-delivery of tariquidar (XR9576) and paclitaxel using long-circulating liposomes. Int. J. Pharmaceut. 2011, 416, 296-299. [CrossRef] [PubMed]

32. Sawicka, E.; Saczko, J.; Roik, J.; Kulbacka, J.; Piwowar, A. Effect of Interaction between 17ß-Estradiol, 2-Methoxyestradiol and 16 $\alpha$-Hydroxyestrone with Chromium (VI) on Ovary Cancer Line SKOV-3: Preliminary Study. Molecules 2020, 25, 5214. [CrossRef] [PubMed]

33. Zhao, L.; Au, J.L.; Wientjes, M.G. Comparison of methods for evaluating drug-drug interaction. Front. Biosci. 2010, 2, $241-249$.

34. Novickij, V.; Rembiałkowska, N.; Staigvila, G.; Kulbacka, J. Effects of extracellular medium conductivity on cell response in the context of sub-microsecond range calcium electroporation. Sci.Rep. 2020, 10, 3718-3730. [CrossRef] [PubMed] 